\title{
Is Sleep Quality Associated with Restless Legs Syndrome in Patients Suffering from Multiple Sclerosis?
}

\author{
Marzieh Khatooni, ${ }^{1}$ Fatemeh Samiee-Siboni, ${ }^{2}$ Zainab Alimoradi, ${ }^{2,}{ }^{,}$Vajieh Atashi, ${ }^{3}$ and Maryam \\ Momeni ${ }^{1}$ \\ ${ }^{1}$ Faculty of Nursing and Midwifery, Iran University of Medical Sciences, Tehran, IR Iran \\ ${ }^{2}$ Faculty of Nursing and Midwifery, Qazvin University of Medical Sciences, Qazvin, IR Iran \\ ${ }^{3}$ Faculty of Nursing and Midwifery, Isfahan University of Medical Sciences, Isfahan, IR Iran \\ "Corresponding author: Zainab Alimoradi, Qazvin University of Medical Sciences, Bahonar blv. Postal code: 34197-59811, Qazvin, IR Iran. Tel: +98-2833336001-5, Fax: \\ +98-2833237268, E-mail: zainabalimoradi@yahoo.com
}

Received 2017 April 03; Revised 2017 June 14; Accepted 2017 August 16.

\begin{abstract}
Background: Restless legs syndrome (RLS) is a type of movement disorder with strong importunate movement of legs during rest or inactivity. Twitching of muscle is experienced at night that disturbs patients' sleep. This syndrome is more prevalent among patients with multiple sclerosis (MS). Hence, this study aimed to investigate the association between restless legs syndrome and sleep disturbances in patients suffering from MS.

Methods: This cross-sectional study was conducted from May to September 2016 in Qazvin, Iran. Participants were 118 patients with MS referring to the multiple sclerosis association. Data were collected using a demographic questionnaire, expanded disability status scale (EDSS) to screen and assess the intensity of restless legs syndrome, and Pittsburgh sleep quality index to investigate sleep disturbance. Descriptive and inferential statistics including independent T test, 2 test, and stepwise logistic regression analysis were used for data analysis.

Results: RLS was diagnosed in $56.8 \%$ of the participants. The score of sleep quality was above 6 indicating poor sleep quality in the patients. However, the mean score of PSQI was significantly higher in patients suffering from restless legs syndrome compared to the healthy people $(14.43 \pm 2.2$ and $11.43 \pm 2.2$, respectively; $\mathrm{P}<0.001)$.

Conclusions: RLS is a prevalent disorder in MS patients leading to sleep disturbances. Therefore, the assessment, diagnosis, and implementation of appropriate interventions to improve patients' sleep quality are required. Such interventions also can improve patients' health status and quality of life.
\end{abstract}

Keywords: Restless Legs Syndrome, Sleep Disturbance, Multiple Sclerosis

\section{Background}

Sleep is a circadian cycle with a complex biological pattern. Sleep disturbances can have detrimental effects on the immunity system, wound healing, emotional and cognitive functions, functional status, and stress levels (1-3). Delay in patient's recovery, increase in the severity, mortality, and morbidity of diseases, and doubling the number of hospital admissions per month are some consequences of sleep disturbances $(4,5)$.

Sleep disturbances or insomnia syndrome are defined as below: experience of more than three nights of insomnia through a week, difficultly in falling asleep or awakenings for more than 30 min during night time, impaired sleep efficiency with less than $85 \%$ time spent in bed for sleep, impaired daily functions, and considerable distress (6). Insomnia, breathing problems in sleep, disorders related to circadian rhythm, restless legs syndrome, narcolepsy, and rapid eye movement (REM) are common sleep disorders among patients with multiple sclerosis (MS) (7).

Risks of comorbidity associated with sleep problems are higher in MS. Bamer et al. (2008) reported more sleep difficulties among patients with MS compared to the general population. In addition, with a prevalence of 51.5\% of moderate to severe sleep disturbances, women with MS appeared to be at a higher risk compared to men (8). Brass et al. (2010) reported less sleep disorders in the general population in comparison with patients with MS. In addition, it might present as fatigue, which is the most prevalent and weakening symptom of MS (7).

Restless legs syndrome (RLS) is known as a substantial cause of sleep disturbance in many neurological disorders (9). RLS refers to a neurological condition in which the patients are urging to move legs. Simultaneously they have a sense of inconvenience in legs (10). Patients feel this sense especially in the evening or at night when they are at rest or inactive. Moving legs is a typical way to relieve these sensations (11). 
RLS is most often associated with several medical conditions including renal failure, iron deficiency, diabetes, pregnancy, neuropathies, rheumatoid arthritis, Parkinson's diseases, myelopathies, spin cerebellar ataxias, and intake of specific drugs such as antagonists of dopamine, lithium, and antidepressants (12). Among neurologic disorders, RLS is associated significantly with MS particularly in persons with severe sensory and pyramidal disabilities. It is believed that the correlation of inflammatory damage with MS may lead to a secondary RLS (13). Higher rate of RLS in MS patients versus the control group was reported in some studies (12-14). Nevertheless, Gomez et al. (2007) did not report any statistical difference in the prevalence of RLS when comparing two groups of MS and control (15).

A few studies have assessed the association between sleep quality and RLS in patients suffering from MS. Moreira et al. (2008) showed associations between fatigue, sleep quality, clinical disabilities, and RLS among patients with MS (16). Li et al. (2012) also studied the association between RLS, other sleep disorders, and MS in a group of women. They reported that the prevalence of daytime sleepiness and RLS was significantly higher among women with MS (17). Given variations in RLS prevalence in different populations, this study was designed to investigate the association between RLS and sleep difficulties in a group of patients with MS.

\section{Methods}

\subsection{Study Design and Participants}

This cross-sectional study was implemented from May to September 2016 on MS patients. The participants were the members of MS association in Qazvin, Iran. The following criteria were used to exclude the patients: other neurologic disorders, pregnancy, specific diseases related to or induced by RLS, previously or currently being treated by clonazepam, using agonists of dopamine (except for the diagnosis of RLS), being treated by anti-dopaminergic (neuroleptic) compounds, and having history of abusing drug or alcohol. Patients with the recent diagnosis of MS (within 1 year prior to the study), having clinical relapse of MS recently (about three months prior to the study), and being treated with steroids during the last 3 months prior to the study were excluded, as well. No specific limitations were considered with regard to the chronic treatment of MS such as interferon, cyclophosphamide, or azathioprine. According to above-mentioned criteria, 118 out of 270 patients from the MS association were eligible to enter the study.

\subsection{Data Collection}

Patients were interviewed to collect data in the MS association. The criteria of international restless legs syndrome study group were used for data collection. RLS and its severity were determined using international restless legs syndrome rating scale (EDSS). The Pittsburgh sleep quality index (PSQI) was used to assess sleep quality. In addition, patients' demographic characteristics including age, gender, education level, marital status, work status, and duration of disease were recorded. The expanded disability status scale was used to assess patients' disability status.

\subsection{Intensity of $M S$}

The EDSS (18) is the standard questionnaire in clinical trials and clinical practice to measure the progression of disease and the degree of neurological impairments. In this study, EDSS self-reporting version was used. The results obtained from this version have shown a strong correlation with those of the scale administered by physicians. In addition, this version has had a similar inter-rater reliability to two physician-administered ones (19). According to EDSS, patients' functions are divided into eight functional systems of cerebellar, pyramidal, brainstem, cerebral, sensory, bowel and bladder, visual, and others. Each functional system is graded based on having impairment, and then the scores are summed across these systems. The total score gained from this scale ranges from 0 to 10 . The score zero means the patient did not have any neurological abnormality, and the score 10 means the patient died of MS. The scores between 0.0 - 4.0 were categorized as mild impairment, scores of 4.5 - 6.5 as moderate impairment, and scores of 7.0 - 9.5 as advanced impairment of MS. A patient with mild severity was ambulatory and independent; this patient was able to walk more than $500 \mathrm{~m}$ without aid or rest. Patients whose disease was categorized as moderate severity had limited daily activities. Patients with advanced impairment were restricted to a wheelchair (20).

\subsection{The Assessment RLS}

RLS was assessed based on the criteria suggested by the international restless legs syndrome study group (9) as follows: "Do you have unpleasant legs sensations such as crawling, paresthesia or pain combined with motor restlessness and an urge to move?" to answer this question, a Likert scale of no, less than once per month, 2 - 4 times per month, 5 - 14 times per month, and more than 15 times per month was used. Those who answered 'yes' continued to the following questions: 1) do symptoms happen only when you are resting and does it improve by moving? and 2) do you experience worsening of these symptoms in the 
evening and at night compared to the morning? RLS was considered when a participant reported having symptoms for five times per month and answered 'yes' to the following questions.

The international restless legs syndrome rating scale was used to assess the intensity of RLS (21). This questionnaire had ten items with a 5-point Likert scale. When patients' scores were 0-10, severity was considered as being mild while moderate severity was assumed when patients had scores of 11 to 20 . Scores of 21 to 30 were interpreted as severe RLS, and scores of 31 to 40 meant having very severe RLS.

\subsection{Assessment of Sleep Quality}

Quality of sleep was assessed using PSQI. Patterns and quality of sleep in adults can be measured using PSQI. It differentiates 'poor' from 'good' sleep quality through the measurement of sleep latency, sleep duration, subjective sleep quality, habitual sleep efficiency, sleep disturbances, use of sleep medications, and daytime dysfunction over the last month. Sleep was assessed using a Likert scale from 0 to 3 in the seven mentioned aspects. Patients could acquire scores 0 to 21 on this scale. Having higher scores indicated lower sleep quality and scores above six meant poor sleep quality.

In this study, questionnaires were used that had been translated to Persian and their psychometric properties had been studied in previous studies. Soleimany et al. (2007) and Ghanei et al. (2011) assessed the validity and reliability of the Persian version of the PSQI and reported a reliability coefficient of 0.84 and 0.94 , respectively $(22,23)$. The reliability coefficient reported for the Persian version of the international restless legs syndrome rating scale was 0.95 (24). Habibzade et al. (2011) studied the psychometric properties of international restless legs syndrome rating scale and the PSQI and reported Cronbach's alpha coefficients of $0.90,0.97$, and 0.83 , respectively (25). Moreover, the reliability of these questionnaires was assessed in this study. PSQI and international restless legs syndrome rating scale had Cronbach's alpha coefficients of 0.81 and 0.87 , respectively.

\subsection{Ethical Issues}

The aim of the study was explained to the patients before conducting interviews and they were free to participate in this study. They were ensured regarding anonymity and confidentiality of the data. They could withdraw from the study at any time without being penalized. Only patients who signed an informed consent form were included in this study.

\subsection{Data Analysis}

Data were analyzed using Statistical software package SPSS version 16. Independent T-test was used to compare continuous variables between patients with and without RLS, and the Chi square test was used to analyze categorical variables. In order to examine association of RLS with demographic and clinical variables, stepwise logistic regression analysis was performed. Odds ratios and 95\% confidence interval were computed. The dependent variable was affection of RLS categorized as without RLS and with RLS. The independent variables in the model were age, gender, educational status, marital status, working status, MS duration, MS severity, and total score of PSQI. Significance level was set at 0.05 to analyze the data.

\section{Results}

118 patients were eligible for enrolment in the study. 67 patients (56.8\%) had RLS. The majority of participants (67.8\%) were female and 63.6\% were single. Demographic variables between patients with and without RLS were not statistically different (Table 1).

The mean duration of MS was significantly different between the two groups (3.41 vs. 2.25 years, $\mathrm{P}<0.007$ in patients with and without RLS). The intensity of MS or MSrelated disability was detected as three levels of mild, moderate, and severe. No very severe case was reported. The intensity of MS was not significantly different between the groups (Table 2 ).

The total scores of sleep quality were above 6 for both groups, indicating a poor quality of sleep among participants. The mean scores of sleep quality were significantly different between the patients with and without RLS (14.43 \pm 2.2 vs. $11.43 \pm 2.2$, respectively, $\mathrm{P}<0.001)$. The comparison of the PSQI dimensions showed that sleep duration, sleep latency, sleep disturbances, and daytime dysfunction were significantly different between the groups $(\mathrm{P}<0.05)$ (Table 3).

The RLS severity among the patients was as follows: $41.8 \%$ with mild, $38.2 \%$ with moderate, $14 \%$ with sever, and $6 \%$ with very sever RLS. Nevertheless, two groups had no statistically significant difference according to the severity of RLS, sleep quality ( $\mathrm{P}=0.37)$, intensity of MS $(\mathrm{P}=0.81)$, and demographic variables. However, association between MS duration and suffering from RLS was significant ( $\mathrm{P}=$ 0.007).

Regression analysis revealed that RLS was associated with MS duration $(\mathrm{P}<0.003, \mathrm{OR}=1.651,95 \% \mathrm{CI}=1.183$ 2.306), MS Severity $(\mathrm{P}<0.015, \mathrm{OR}=0.383,95 \% \mathrm{CI}=0.178$ $0.827)$, and total score of PSQI $(\mathrm{P}<0.001, \mathrm{OR}=1.93,95 \% \mathrm{CI}=$ 1.481 - 2.537). Odds of RLS significantly increased by higher 
Table 1. Comparison of Demographic Characteristics of Patients with MS Regarding Their RLS Status ( $\mathrm{n}=118)^{\mathrm{a}}$

\begin{tabular}{|c|c|c|c|c|}
\hline \multirow[t]{2}{*}{ Variable } & & \multicolumn{2}{|c|}{ Having RLS or Not? } & \multirow[t]{2}{*}{ PValue } \\
\hline & & With RLS & Without RLS & \\
\hline Age, $y$ & & $26.28 \pm 6.75$ & $24.80 \pm 4.68$ & 0.163 \\
\hline \multirow{2}{*}{ Gender } & Male & $23(34.3)$ & $15(29.4)$ & \multirow{2}{*}{0.571} \\
\hline & Female & $44(65.7)$ & $36(70.6)$ & \\
\hline \multirow{2}{*}{ Marital status } & Single & $38(56.7)$ & $37(72.5)$ & \multirow{2}{*}{0.077} \\
\hline & Married & $29(43.3)$ & $14(27.5)$ & \\
\hline \multirow{2}{*}{ education level } & Diploma & $43(64.2)$ & $36(70.6)$ & \multirow{2}{*}{0.463} \\
\hline & Bachelor or higher & $24(35.8)$ & $15(29.4)$ & \\
\hline \multirow{5}{*}{ Working status } & Employee & $9(13.4)$ & $2(3.9)$ & \multirow{5}{*}{0.32} \\
\hline & Housewife & $16(23.9)$ & $19(37.3)$ & \\
\hline & Student & $5(6.5)$ & $5(9.3)$ & \\
\hline & Private business & $4(6)$ & $4(7.8)$ & \\
\hline & Unemployed & $33(49.3)$ & $22(43.1)$ & \\
\hline
\end{tabular}

Table 2. Comparison of Clinical Characteristics of Patients with MS Regarding Their RLS Status $(n=118)^{a}$

\begin{tabular}{|c|c|c|c|c|}
\hline \multirow[t]{2}{*}{ Variable } & & \multicolumn{2}{|c|}{ Having RIS or Not? } & \multirow[t]{2}{*}{ PValue } \\
\hline & & With RIS $(N=67)$ & Without RIS $(\mathrm{N}=51)$ & \\
\hline MS duration, $y$ & & $3.41 \pm 2.83$ & $2.25 \pm 1.2$ & 0.007 \\
\hline \multirow[t]{2}{*}{ MS Severity } & Moderate & $27(40.3)$ & $22(43.1)$ & \multirow[t]{2}{*}{0.118} \\
\hline & Sever & $15(29.4)$ & $11(16.4)$ & \\
\hline
\end{tabular}

Abbreviation: RLS, restless legs syndrome.

${ }^{\mathrm{a}}$ Values are expressed as mean $\pm \mathrm{SD}$ or No. (\%).

Table 3. Comparison of the PSQI Dimensions Between Patients with MS $(\mathrm{N}=67)$ and Without $(\mathrm{N}=51) \mathrm{RLS}^{\mathrm{a}}$

\begin{tabular}{|lccc}
\hline Sleep Dimensions of the PSQI & With RLS & Without RLS & P Value \\
\hline Subjective quality of sleep & $1.61 \pm 1.02$ & $1.35 \pm 1.05$ & 0.183 \\
\hline Sleep latency & $1.68 \pm 0.89$ & $1.21 \pm 0.94$ & 0.007 \\
\hline Sleep duration & $1.73 \pm 0.9$ & $1.01 \pm 0.88$ & 0.001 \\
\hline Habitual sleep efficiency & $3 \pm 0$ & $3 \pm 0$ & - \\
\hline Sleep disturbances & $1.98 \pm 0.32$ & $1.66 \pm 0.55$ & 0.001 \\
\hline Use of sleeping medication & $1.74 \pm 1.11$ & $1.29 \pm 1.15$ & 0.34 \\
\hline Daytime dysfunction & $2.61 \pm 0.57$ & $1.88 \pm 0.71$ & 0.001 \\
\hline Total score of the PSQI & $14.43 \pm 2.2$ & $11.43 \pm 2.2$ & 0.001 \\
\hline
\end{tabular}

Abbreviation: RLS, restless legs syndrome.

${ }^{\mathrm{a}}$ Values are expressed as mean $\pm \mathrm{SD}$.

scores of PSQI (poorer quality of sleep)and longer duration of MS whilst it decreased by higher MS severity (Table 4).

\section{Discussion}

While RLS is a common cause of sleep disturbances, it is rarely diagnosed. Patients often do not seek medical care or mistakenly attribute their symptoms to anxiety and stress. Therefore, misdiagnosis is one of the most important barriers to epidemiological studies regarding RLS (26). Our result showed that $56.8 \%$ of the MS patients suffered from RLS, too. However, other studies reported a prevalence of 13.3 to $47.5 \%(7,13,14)$. Due to ethnological differences, the existence of predisposing factors, environmental factors such as geographical position and methodological limitations such as sample size may lead to great inconsistency in reported prevalence of RLS in different populations and settings (25). The possible reason for higher prevalence of RLS found in this study might be due to precise inclusion/exclusion criteria of the present study.

Association of RLS with quality of sleep was significant in this study, which shows that patients with RLS had higher scores of sleep disturbances $(\mathrm{P}<0.001)$. This is consistent with previous studies. For instance, Manconi et al. (2008) reported that sleep disorders and the use of sleep pills are more prevalent among patients with MS suffering 
Table 4. Logistic Regression Model of Influencing Variables on RLS

\begin{tabular}{|c|c|c|c|c|c|}
\hline \multirow[t]{2}{*}{ Variable } & \multirow[t]{2}{*}{$\mathbf{B}$} & \multirow[t]{2}{*}{ OR } & \multicolumn{2}{|c|}{ 95\% Confidence Interval } & \multirow[t]{2}{*}{ PValue } \\
\hline & & & Lower & Upper & \\
\hline MS duration & 0.502 & 1.651 & 1.183 & 2.306 & 0.003 \\
\hline MS Severity & -0.959 & 0.383 & 0.178 & 0.827 & 0.015 \\
\hline Total score of PSQI & 0.662 & 1.938 & 1.481 & 2.537 & 0.001 \\
\hline
\end{tabular}

from RLS $(\mathrm{P}<0.05)$. They emphasized a significant association between RLS and sleep quality among patients with MS (13). In another study, Holmes et al. (2007) reported that out of 152 patients suffering from RLS, 79\% experienced sleep disturbances (27). In addition, Moreira et al. (2008) found that RLS is significantly associated with sleep quality, sleep disturbances, and excessive daytime sleepiness $(P=0.02)(16)$. Moreover, Li et al. (2012) reported that the prevalence of RLS and daytime sleepiness is significantly higher among women who suffer from MS and the risk of developing RLS in the future are higher in this group, as well (17). Therefore, due to the high prevalence of RLS and its' worsening effect on sleep quality, the assessment of RLS should be of great consideration in patients with MS.

This study showed that MS duration had a significant association with RLS ( $\mathrm{P}<0.007)$; thus, patients with RLS had significantly longer MS duration. The present study was consistent with the study of Manconi et al. (2008) who reported a significant association between RLS and MS duration although unlike the current study, they found that age and severity of MS in patients were significantly associated with RLS (13). The findings of this study was consistent with the results of Moreira's study (2008), indicating that RLS was not significantly associated with age, gender, and severity of MS $(\mathrm{P}<0.05)(16)$.

In the present study, RLS was moderate to severe in $52.2 \%$ of the patients. Comparison of the patients with moderate to severe RLS with those having any other type of persistent sleep disorders showed that RLS could cause less sleep (28). RLS can also cause great difficulties in falling asleep since getting to sleep needs a period of rest and usually coincides with the initiation of RLS symptoms. Almost $70 \%$ of the patients with RLS take more than half an hour to fall asleep (29). About 15\% take two or more hours to fall asleep and patients who suffer from moderate to severe forms of RLS may have less than five hours of sleep over night (9). About $60 \%$ of such patients wake up three or more times each night (29) and about 80\% experience periodic intermittent movements of legs during sleep, which can lead to sleep disturbance (9). In addition, RLS could have worsening effects on patients' quality of life. Patients suffering from RLS report significant deficits in physical functioning, role functioning, general health, mental health, vitality, and increased bodily pain compared to the general population $(30,31)$.

\subsection{Conclusions}

RLS is prevalent among patients suffering from MS and can cause higher sleep disturbances in long-term. Therefore, the assessment, diagnosis, and implementation of appropriate interventions to improve patients' sleep quality are required. Such interventions also can improve patients' quality of life and health status.

\section{Acknowledgments}

Authors should express their sincere gratitude to patients with MS and the MS association staff for their participation in this research project.

\section{Footnote}

Conflict of Interest: There is no conflict of interest to be declared.

\section{References}

1. Williams S. Mental health psychiatric nursing. Philadelphia: Mosby; 1993.

2. Dinges DF, Douglas SD, Zaugg L, Campbell DE, McMann JM, Whitehouse WG, et al. Leukocytosis and natural killer cell function parallel neurobehavioral fatigue induced by 64 hours of sleep deprivation. $J$ Clin Invest. 1994;93(5):1930-9. doi:10.1172/JCI117184. [PubMed: 7910171].

3. Krachman SL, D'Alonzo GE, Criner GJ. Sleep in the intensive care unit. Chest. 1995;107(6):1713-20. [PubMed: 7781373].

4. Nicholson T, Patel J, Sleigh JW. Sleep patterns in intensive care unit patients: a study using the bispectral index. Crit Care Resusc. 2001;3(2):86-91. [PubMed:16610990].

5. Tamburri LM, DiBrienza R, Zozula R, Redeker NS. Nocturnal care interactions with patients in critical care units. Am J Crit Care. 2004;13(2):102-12. [PubMed: 15043238] quiz 114-5.

6. Howell D, Oliver TK, Keller-Olaman S, Davidson JR, Garland S, Samuels $\mathrm{C}$, et al. Sleep disturbance in adults with cancer: a systematic review of evidence for best practices in assessment and management for clinical practice. Ann Oncol. 2013;25(4):791-800.

7. Brass SD, Duquette P, Proulx-Therrien J, Auerbach S. Sleep disorders in patients with multiple sclerosis. Sleep Med Rev. 2010;14(2):121-9. doi: 10.1016/j.smrv.2009.07.005. [PubMed: 19879170]. 
8. Bamer AM, Johnson KL, Amtmann D, Kraft GH. Prevalence of sleep problems in individuals with multiple sclerosis. Mult Scler. 2008;14(8):1127-30. doi: 10.1177/1352458508092807. [PubMed: 18632776].

9. Allen RP, Picchietti D, Hening WA, Trenkwalder C, Walters AS, Montplaisi J. Restless legs syndrome: diagnostic criteria, special considerations, and epidemiology. Sleep Med. 2003;4(2):101-19. doi: 10.1016/s1389-9457(03)00010-8.

10. Trenkwalder C, Paulus W. Restless legs syndrome: pathophysiology, clinical presentation and management. Nat Rev Neurol. 2010;6(6):33746. doi: 10.1038/nrneurol.2010.55. [PubMed: 20531433].

11. Ekbom $\mathrm{K}$, Ulfberg J. Restless legs syndrome. J Intern Med. 2009;266(5):419-31. doi: 10.1111/j.1365-2796.2009.02159.x. [PubMed: 19817966].

12. Deriu M, Cossu G, Molari A, Murgia D, Mereu A, Ferrigno P, et al. Restless legs syndrome in multiple sclerosis: a case-control study. Mov Disord. 2009;24(5):697-701. doi: 10.1002/mds.22431. [PubMed: 19117365].

13. Italian RSG, Manconi M, Ferini-Strambi L, Filippi M, Bonanni E, Iudice A, et al. Multicenter case-control study on restless legs syndrome in multiple sclerosis: the REMS study. Sleep. 2008;31(7):944-52.[PubMed: 18655317].

14. Canturk IA, Turkes M, Isik N, Aydin T, O OAD, Candan F. Restless legs syndrome in multiple sclerosis. 26th Congress of the European Committee for Treatment and Research in Multiple Sclerosis (ECTRIMS) \& 15th Annual Conference of Rehabilitation in MS (RIMS). .

15. Gomez-Choco MJ, Iranzo A, Blanco Y, Graus F, Santamaria J, Saiz A. Prevalence of restless legs syndrome and REM sleep behavior disorder in multiple sclerosis. Mult Scler. 2007;13(6):805-8. doi: 10.1177/1352458506074644. [PubMed: 17613610].

16. Moreira NC, Damasceno RS, Medeiros CA, Bruin PF, Teixeira CA, Horta WG, et al. Restless leg syndrome, sleep quality and fatigue in multiple sclerosis patients. Braz J Med Biol Res. 2008;41(10):932-7. [PubMed: 19030714].

17. Li Y, Munger KL, Batool-Anwar S, De Vito K, Ascherio A, Gao X. Association of multiple sclerosis with restless legs syndrome and other sleep disorders in women. Neurology. 2012;78(19):1500-6. doi: 10.1212/WNL.ob013e3182553c5b. [PubMed: 22539566].

18. Kurtzke JF. Rating neurologic impairment in multiple sclerosis: an expanded disability status scale(EDSS). Neurology. 1983;33(11):1444-52. [PubMed: 6685237].

19. Bowen J, Gibbons L, Gianas A, Kraft GH. Self-administered Expanded Disability Status Scale with functional system scores correlates well with a physician-administered test. Mult Scler. 2001;7(3):201-6. doi: 10.1177/135245850100700311. [PubMed: 11475445].

20. Chwastiak L, Ehde DM, Gibbons LE, Sullivan M, Bowen JD, Kraft
GH. Depressive symptoms and severity of illness in multiple sclerosis: epidemiologic study of a large community sample. Am J Psychiatry. 2002;159(11):1862-8. doi: 10.1176/appi.ajp.159.11.1862. [PubMed 12411220].

21. Walters AS, LeBrocq C, Dhar A, Hening W, Rosen R, Allen RP. Validation of the International Restless Legs Syndrome Study Group rating scale for restless legs syndrome. Sleep Med. 2003;4(2):121-32. doi 10.1016/s1389-9457(02)00258-7.

22. Ghanei R, Hemati-Maslak-Pak M, Ghosi S, Hossein-Pour H, Amin-Pour E, Baghi V. Restless legs syndrome and the quality of sleep in type II diabetes. Feyz J Kashan Univ Med Sci. 2011;15(3).

23. Soleimany M, Ziba FN, Kermani A, Hosseini F. Comparison of sleep quality in two groups of nurses with and without rotation work shift hours. Iran J Nurs. 2007;20(49):29-38.

24. Molahosseini S, Mohammadzadeh S, Kamali P. Frequency of sleep disorder and restless legs syndrome in patients referring to hemodialysis units in university hospitals in Tehran in 2003. Med Sci J Islamic Azad Univ Tehran Med Branch. 2005;15(1):27-30.

25. Habibzade H, Khalkhali H, Ghaneii R. Study of the relationship between restless legs syndrome and sleep disturbance among patients in Critical Care Units. J Crit Care Nurs. 2011;4(3):153-8.

26. Stiasny-Kolster K, Trenkwalder C, Fogel W, Greulich W, Hahne M, Lachenmayer L, et al. Restless legs syndrome-new insights into clinical characteristics, pathophysiology, and treatment options. J Neurol. 2004;251 Suppl 6:VI/39-43. [PubMed: 15675724].

27. Holmes R, Tluk S, Metta V, Patel P, Rao R, Williams A, et al. Nature and variants of idiopathic restless legs syndrome: observations from 152 patients referred to secondary care in the UK. J Neural Transm (Vienna). 2007;114(7):929-34. doi: 10.1007/s00702-006-0614-3. [PubMed: 17238008]

28. Allen RP, Earley CJ. Restless Legs Syndrome. J Clin Neurophysiol 2001;18(2):128-47. doi:10.1097/00004691-200103000-00004.

29. Hening W, Walters AS, Allen RP, Montplaisir J, Myers A, Ferini-Strambi L. Impact, diagnosis and treatment of restless legs syndrome (RLS) in a primary care population: the REST (RLS epidemiology, symptoms, and treatment) primary care study. Sleep Med. 2004;5(3):237-46. doi: 10.1016/j.sleep.2004.03.006. [PubMed: 15165529].

30. Abetz L, Allen RP, Follet A, Washburn T, Early C, Kirsch J, et al. Evaluating the quality of life of patients with restless legs syndrome. Clin Ther. 2004;26(6):925-35. doi:10.1016/s0149-2918(04)90136-1.

31. Kushida C, Martin M, Nikam P, Blaisdell B, Wallenstein G, FeriniStrambi L, et al. Burden of restless legs syndrome on health-related quality of life. Qual Life Res. 2007;16(4):617-24. doi: 10.1007/s11136-006 9142-8. [PubMed: 17268935]. 